\title{
Laser Cleaning Iron Meteorite Corrosion, A Microstructural and Compositional Examination
}

Edward P. Vicenzi ${ }^{1}$, Rebecca A. Kaczkowski ${ }^{1}$, and Bartosz A. Dajnowski ${ }^{2}$

1. Museum Conservation Institute, Smithsonian Institution, Suitland, MD, USA

2. Conservation of Sculpture and Objects Studio, Inc., Forest Park, IL, USA

Corrosion of iron meteorite specimens presents a long standing issue facing museum curators, collection staff, and conservators. Surfaces of these specimens readily oxidize upon contact with atmospheric moisture and other environmental contaminants. Corrosion of the most common extraterrestrial FeNi minerals (kamacite and taenite) results in the formation of goethite $[\mathrm{FeO}(\mathrm{OH})]$, lepidocrocite $[\gamma-\mathrm{FeO}$ $(\mathrm{OH})]$, akaganéite [FeO $(\mathrm{OH}, \mathrm{Cl})]$, and their Ni-enriched equivalents [1]. A recent study evaluated stateof-the-art conservation lasers, with regard to pulse duration, repetition rate, and energy density, to remove Fe oxide films on samples of semi-precious quartz and an iron meteorite $[2,3]$. This study focuses on textures and compositional changes observed pre-, and post-laser cleaning treatment of a corroded specimen of the Canyon Diablo meteorite.

Laser cleaning was performed with a 70 -watt, solid-state, high frequency $(100 / 400 \mathrm{kHz})$ laser operating at $1064 \mathrm{~nm}$ with pulse widths of $10 / 100 \mathrm{~ns}$ in duration. Energy densities of $0.23,0.31$, and $1.0 \mathrm{j} / \mathrm{cm}^{2}$ were employed to constrain the laser's damage threshold for meteoritic metal. A laser spot size of $250 \mu \mathrm{m}$ was obtained using a $16 \mathrm{~cm}$ focal lens. Photons were delivered via fiber optic cable to a scanning head emitting a circular scan pattern $(2 \mathrm{~cm}$ diameter) with a conical delivery path that allows the beam to interact with the surface from various angles as the leading edge and trailing edge of the scan move across the object. 2D and 3D optical imagery were collected with a Hirox KH-8700 digital light microscope. An Hitachi S3700N scanning electron microscope was operated in variable pressure (VP SEM) mode at $20 \mathrm{kV}$, and a Bruker XFlash 4010 silicon drift detector was used to collect hyperspectral X-ray data.

Iron oxyhydroxides partly coat a saw cut rectangular prism of the Canyon Diablo meteorite. The corrosion products are light brown to deep red brown in color. Some light brown areas are correlated with thin (microns) concentrically banded reaction fronts (Fig. 1). The flat cut surface of the meteorite allows one to readily appreciate the nonuniformity in Fe-oxide thickness; this is particularly noticeable where corrosion has caused local volume changes creating wrinkles in the film, and in some cases blisters that expose layer-by-layer growth banding (Fig. 2). Examination of the specimen following laser cleaning reveals Fe-oxide spherules, a sharp interface between desorbed and undisturbed corrosion, and the morphology of corrosion pits on the metal surface (Figs. 3 and 4). Despite the spherules indicate corrosion products experienced a molten state, for energy densities $<0.3 \mathrm{j} / \mathrm{cm}^{2}$ the meteorite surface remained unaltered. As a result, these experiments show significant promise for the care of metallic corrosion in museum collections using thoughtfully planned laser cleaning.

References:

[1] VF Buchwald and RS Clarke Jr, American Mineralogist 74, (1989), p 656-667.

[2] B Dajnowski and A Dajnowski, In: Science and Art: A Future for Stone (2016), p. 719-728.

[3] RA Kaczkowski, BA Dajnowski and EP Vicenzi, Proceedings of LACONA XI (2017) DOI:

10.12775/3875-4.03, p 47-62. 

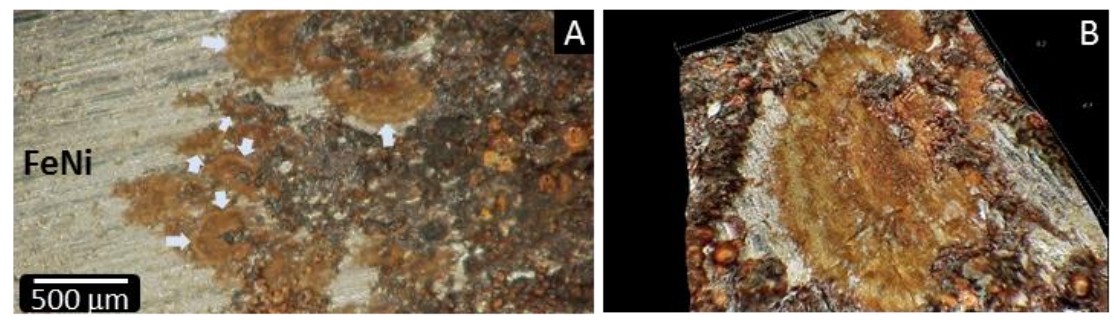

Figure 1. Light microscope imagery of meteoritic metal surface. A) Low magnification view of Fe corrosion. Arrows indicate reaction fronts. B) $3 \mathrm{D}$ view of a concentric diffusive front ( $\mathrm{HFW}=650 \mu \mathrm{m}, \Delta \mathrm{Z} \sim 13 \mu \mathrm{m}$ ).
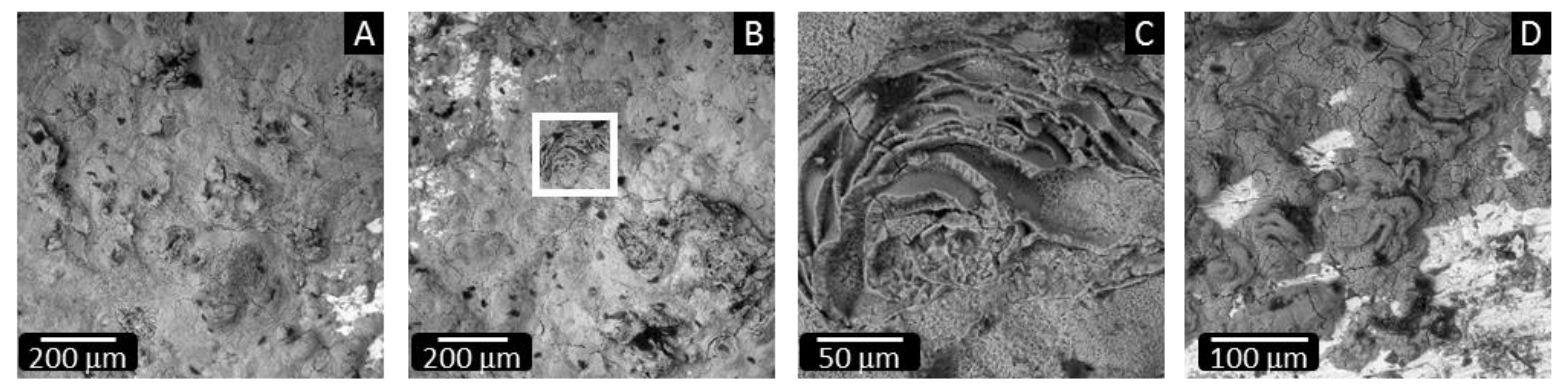

Figure 2. Backscattered electron (BSE) imagery of meteoritic metal corrosion. A,B) lower magnification views of non-uniform corrosion coating. $C$ ) higher resolution image of highlighted area in $B$. D) Locally thicker akaganéite zones.
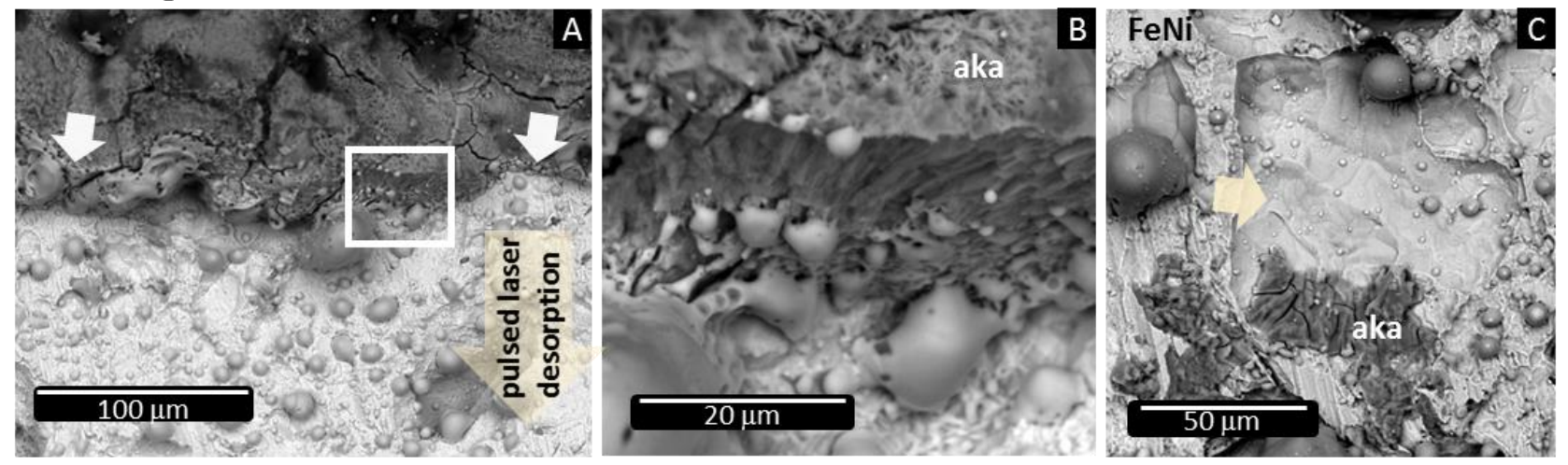

Figure 3. Post laser cleaning BSE imagery. A) Laser cleaned-corrosion interface. B) Higher resolution image of rectangle in $\mathrm{A}$. C) Corrosion pit surface (arrow)and residual akaganéite (aka) and Fe oxide spherules.
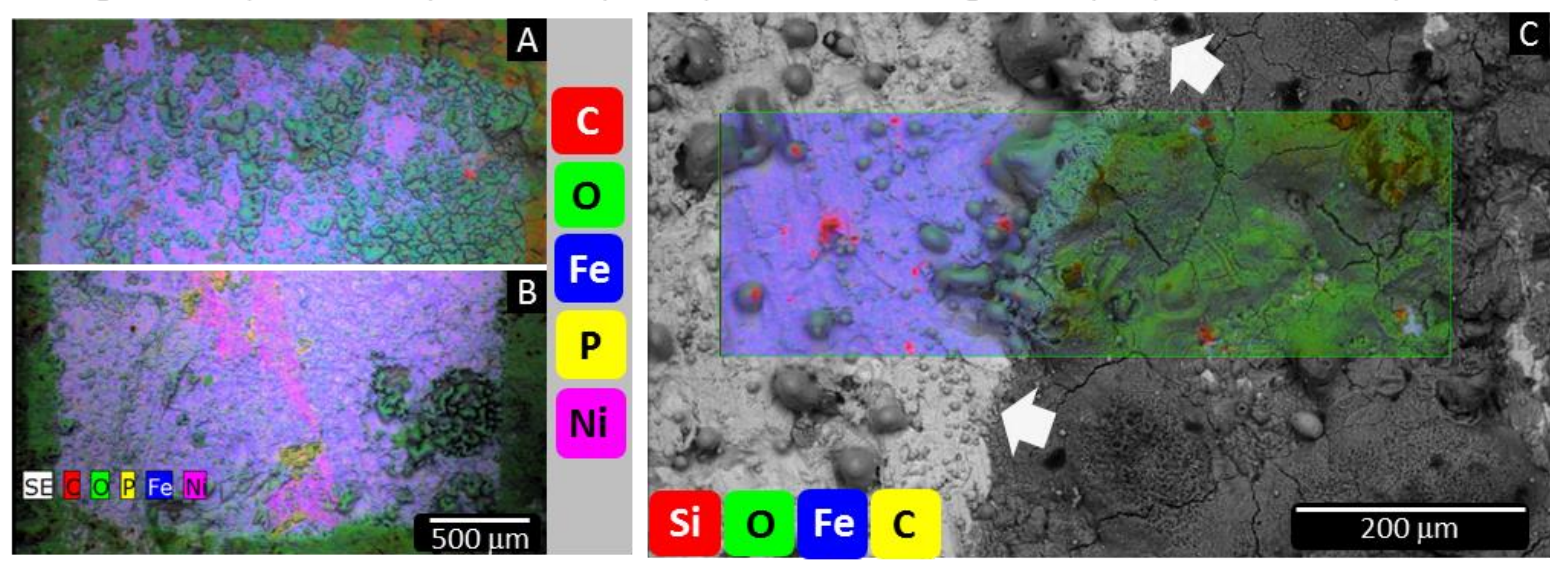

Figure 4. Post laser cleaning $x$-ray imagery superimposed on BSE images for differing laser cleaning conditions. A) Argon flow, $0.23 \mathrm{j} / \mathrm{cm}^{2}$ with $100 \mathrm{~ns}$ pulses. B) Ambient atmosphere, $0.31 \mathrm{j} / \mathrm{cm}^{2}$ with $100 \mathrm{~ns}$ pulses. C) Argon flow using $0.23 \mathrm{j} / \mathrm{cm}^{2}$ with $10 \mathrm{~ns}$ pulses. 